\title{
Calculation of additional heart rates using oxygen consumption and carbon dioxide production: A comparative analysis
}

\author{
JULIAN F. THAYER \\ Pennsyluania State University, University Park, Pennsylvania \\ L. J. P. VAN DOORNEN \\ Free University of Amsterdam, Amsterdam, The Netherlands \\ and \\ J. RICK TURNER \\ University of North Carolina, Chapel Hill, North Carolina
}

\begin{abstract}
Research, to date, on the occurrence of additional heart rates during behavioral stressors has employed oxygen consumption as the index of metabolic activity. Although this is the obvious first choice, in certain situations measures of carbon dioxide production may be more readily obtained. The analysis presented in this paper explored the intuitively appealing notion that, since oxygen consumption and carbon dioxide production are themselves intimately related, carbon. dioxide-production measures may also be appropriate in the "additional heart rate" methodology. Data from the most recent additional-heart-rate paper by Turner and colleagues were thus reexamined, and additional heart rates during mental arithmetic and a video game were separately calculated for the 24 subjects by first using oxygen consumption and then by using carbon dioxide production. The values obtained were very highly correlated; the coefficients for the task periods themselves were 0.99 and 0.96 , respectively. Use of carbon-dioxide-production data in this manner would, therefore, seem to be appropriate.
\end{abstract}

Assessment of the metabolic status of large-magnitude cardiac responses during behavioral stressors has been a recent area of keen investigation within psychophysiology. Attention has focused on these responses because they may be influential in the etiology of hypertension (Obrist, 1981) and, even if they are not causally involved, they may still be markers for its later development (Manuck \& Krantz, 1986). From either standpoint, these cardiac increases are of interest only inasmuch as they are over and above those necessitated by concurrent metabolic demand; metabolically appropriate cardiac activity is not likely to be associated with pathophysiology.

The most compelling evidence of suprametabolic cardiac activity has come from studies that have continuously assessed cardiac and metabolic parameters during both psychological stressors and graded physical exercise;

Preparation of this manuscript was supported by Grant HL 31533 and by the Minority Faculty Development Office of PSU. Requests for reprints should be addressed to Julian F. Thayer, 416 Moore Building, Pennsylvania State University, University Park, PA 16802 , or to J. Rick Turner, Department of Psychiatry, CB 7175, Medical Research Building A, University of North Carolina, Chapel Hill, NC 27599-7175. the orderly relationship that exists between cardiac and metabolic activity during physical work provides an excellent comparator against which to evaluate any possible deviations during psychological challenge. This line of inquiry was pioneered by Blix and colleagues, who reported evidence of metabolically exaggerated heart rates, that is, additional heart rates, during flight maneuvers and parachute training (Blix, Stromme, \& Ursin, 1974; Stromme, Wikeby, Blix, \& Ursin, 1978). In the laboratory, this methodology has been used to document cardiacmetabolic uncoupling during various behavioral stressors (e.g., Sherwood, Allen, Obrist, \& Langer, 1986; Stoney, Langer, \& Gelling, 1986; Turner \& Carroll, 1985; for a review, see Turner, in press).

All of this research has employed oxygen consumption, the logical first choice, as the index of metabolic activity. However, because of its excessive expense, the equipment needed to obtain measures of oxygen consumption is often not readily available in the average psychophysiology laboratory. Although researchers past (Obrist, 1981) and present (Johnston, Anastasiades, Vogele, Kitson, \& Steptoe, 1989) have used muscle activity (EMG) recorded from various locations to index metabolic activity, another pos- 
sible alternative exists. Carbon dioxide production can be obtained with the use of highly accurate, relatively low-cost infrared gas analyzers. These analyzers can be as little as one-third the cost, as well as more accurate than, $\mathrm{O}_{2}$ analyzers (Fishman, 1980; W. L. Kenny, personal communication, March 1990). It therefore becomes necessary to verify that such a strategy would be appropriate. Thus, this paper reexamines data collected during the most recent "additional heart rate" experiment reported by Turner and colleagues (Turner, Carroll, Costello, \& Sims, 1988). Although carbon-dioxide-production data were collected, they were not reported at that time, because primary interest then lay with oxygen consumption. Thus, calculation of additional heart rates with the use of heart rate and carbon dioxide production was now possible; these values were compared with those calculated "traditionally" with the use of heart rate and oxygen consumption.

\section{METHOD}

Full details are reported in Turner et al. (1988). In summary, 24 young, healthy males undertook the psychological challenges of mental arithmetic and a video game. Each of these challenges consisted of an actual task period and a pretask rest (baseline) period. The subjects also completed a graded isotonic-exercise task on a bicycle ergometer. All task periods were $4 \mathrm{~min}$ in duration. Heart rate was continuously monitored during all tasks with a Beckman type R511A dynograph, and oxygen consumption and carbon dioxide production were measured and automatically printed out by a Beckman Metabolic Measurement Chart (see Turner, Carroll, \& Courtney, 1983). A Beckman OM-11 oxygen analyzer was used to measure the oxygen concentration, and a Beckman LB-2 carbon dioxide analyzer was used to measure the carbon dioxide

Table 1

Mean Physiological Values for Heart Rate (HR), Oxygen Consumption $\left(\mathrm{VO}_{2}\right)$, and Carbon Dioxide Production (VCO for All Measurement Periods

\begin{tabular}{|c|c|c|c|c|c|c|}
\hline $\begin{array}{l}\text { Measurement } \\
\text { Period }\end{array}$ & HR & $S D$ & $\mathrm{VO}_{2}$ & $S D$ & $\mathrm{VCO}_{2}$ & $S D$ \\
\hline \multicolumn{7}{|c|}{ Mental Arithmetic } \\
\hline $\begin{array}{l}\text { Baseline } \\
\text { Task }\end{array}$ & $\begin{array}{l}70.7 \\
80.6\end{array}$ & $\begin{array}{l}12.0 \\
17.1\end{array}$ & $\begin{array}{l}312.9 \\
386.5\end{array}$ & $\begin{array}{l}73.0 \\
80.6\end{array}$ & $\begin{array}{l}251.7 \\
323.3\end{array}$ & $\begin{array}{l}59.7 \\
88.5\end{array}$ \\
\hline \multicolumn{7}{|c|}{ Video Game } \\
\hline $\begin{array}{l}\text { Baseline } \\
\text { Task }\end{array}$ & $\begin{array}{l}70.9 \\
80.3\end{array}$ & $\begin{array}{l}13.2 \\
17.0\end{array}$ & $\begin{array}{l}313.0 \\
426.7\end{array}$ & $\begin{array}{l}71.1 \\
82.7\end{array}$ & $\begin{array}{l}247.9 \\
338.1\end{array}$ & $\begin{array}{l}49.0 \\
73.6\end{array}$ \\
\hline \multicolumn{7}{|c|}{ Exercise } \\
\hline $\begin{array}{l}\text { Rest } \\
\text { Level } 1 \\
\text { Level } 2 \\
\text { Level } 3 \\
\text { Level } 4\end{array}$ & $\begin{array}{r}71.7 \\
85.7 \\
92.1 \\
102.3 \\
112.9\end{array}$ & $\begin{array}{l}11.4 \\
11.4 \\
11.1 \\
12.0 \\
13.2\end{array}$ & $\begin{array}{r}401.5 \\
858.3 \\
1,114.0 \\
1,374.0 \\
1,683.5\end{array}$ & $\begin{array}{r}69.4 \\
116.5 \\
126.2 \\
139.2 \\
161.0\end{array}$ & $\begin{array}{r}274.0 \\
598.0 \\
812.1 \\
1,058.8 \\
1,351.5\end{array}$ & $\begin{array}{r}53.1 \\
104.6 \\
124.5 \\
141.5 \\
164.0\end{array}$ \\
\hline
\end{tabular}

Note-HR measured in beats per minute (bpm). $\mathrm{VO}_{2}$ and $\mathrm{VCO}_{2}$ measured in milliliters per minute (mlpm). $N=24$.
Table 2

Mean Additional-Heart-Rate Values (bpm) Calculated from Oxygen Consumption $\left(\mathrm{VO}_{2}\right)$ and Carbon Dioxide Production $\left(\mathrm{VCO}_{2}\right)$

\begin{tabular}{|c|c|c|c|c|c|c|c|c|}
\hline \multirow{2}{*}{$\begin{array}{c}\text { Metabolic } \\
\text { Index }\end{array}$} & \multicolumn{4}{|c|}{ Mental Arithmetic } & \multicolumn{4}{|c|}{ Video Game } \\
\hline & Baseline & $S D$ & Task & $S D$ & aseline & $S D$ & Task & $S D$ \\
\hline & & $\begin{array}{l}3.1 \\
3.6\end{array}$ & & 8.3 & & 5.0 & & \\
\hline
\end{tabular}

$\overline{\text { Note }-N}=24$.

concentration, in the expired gas. These are typical gas analyzers that are used in human applications.

\section{RESULTS}

Mean physiological values for heart rate, oxygen consumption, and carbon dioxide production for all measurement periods are presented in Table 1. Additional heartrate scores were calculated in two ways: the traditional way, which used heart-rate and oxygen-consumption values, and the way that used heart-rate and carbon-dioxideproduction values.

Heart-rate and oxygen-consumption values. For each subject, values derived from the exercise task were used to obtain a regression of heart rate on oxygen consumption. Individual correlation coefficients ranged from 0.970 to 0.999 , with a mean of 0.992 ; all were highly significant $(p<.01)$, bearing witness to the quality of fit in all cases. The regression equations were then used in conjunction with the oxygen-consumption values derived from the psychological-task periods to predict heart-rate values for each period; the arithmetic difference, actual heart rate minus predicted heart rate, was called additional heart rate. Additional-heart-rate scores were thus calculated for each subject for all psychological-task periods; the means are presented in Table 2.

Heart-rate and carbon-dioxide-production values. The same procedure was then repeated, employing carbondioxide-production values instead of oxygen-consumption values. In this case, the individual correlations associated with the regression equations ranged from 0.897 to 0.999 , with a mean of 0.990 . All except the lowest value were highly significant $(p<.01)$, and the lowest value attained significance at the $p<.05$ level, again bearing witness to their quality of fit. The additional heart rates that were then calculated are also presented in Table 2.

Comparison of the two sets of additional heart rates. Inspection of the means presented in Table 2 indicates that the mean heart rate/carbon dioxide additional-heart-rate values are consistently around $3 \mathrm{bpm}$ lower than the mean heart rate/oxygen values. A similar spread around the means is indicated by the similar standard deviations and is further evidenced by the range of values observed: For example, the ranges of heart rate/oxygen values for the mental arithmetic and video game task periods were -0.5 to $37.3 \mathrm{bpm}$ and -2.3 to $33.0 \mathrm{bpm}$, respectively; the 
respective heart rate/carbon dioxide additional heart rates were -4.5 to $36.3 \mathrm{bpm}$ and -4.8 to $24.4 \mathrm{bpm}$.

Although this inspection is suggestive of a close relationship between the two sets of values, correlational analysis provided clear-cut evidence. For mental-arithmetic baseline and task periods and video-game baseline and task periods, the coefficients were $0.88,0.99,0.91$, and 0.96 , respectively; all four were highly significant $(p<.001)$.

\section{DISCUSSION}

The simple conclusion to be drawn from this analysis is that there is an extremely close relationship between additional heart rates calculated with the use of oxygenconsumption data and those calculated with the use of carbon dioxide production under standard conditions. Although this relationship is theoretically predicted and might have been anticipated, the use of carbon-dioxideproduction data in such a manner demands this rigorous demonstration.

The fact that the magnitude of "carbon dioxide" additional heart rates tends to be about $3 \mathrm{bpm}$ smaller than "oxygen" additional heart rates is also predicted by established physiological theory. The amount of $\mathrm{CO}_{2}$ expired is normally less than the amount of $\mathrm{O}_{2}$ inspired because of a number of factors, including the amount of oxygen that is stored in the lungs. This is reflected in the respiratory quotient $\left(\mathrm{RQ}: \mathrm{CO}_{2} / \mathrm{O}_{2}\right)$, which normally is somewhat less than unity (Mines, 1986). Thus, the absolute magnitude of the additional heart rate is not crucial. In research linking metabolically excessive cardiac activity to risk of pathophysiology, the more important consideration is the range of individual differences observed (see Turner, 1989). Since there is no absolute heart-ratechange value that delineates high from low reactors, the correlations presented show that the individual differences evident in one set of additional-heart-rate values are extremely well reflected in the other set. Designation of high and low reactors, and relative high- and low-risk categorization within a given subject sample, would thus be extremely similar whichever method were employed.

Although the use of carbon-dioxide-production data in assessing the metabolic relevance of concurrent cardiac activity is thus given credence, a note of caution is in order. During situations such as the present experiment, when the necessary assumptions of the additional-heartrate methodology are met, $\mathrm{VCO}_{2}$ and $\mathrm{VO}_{2}$ will both yield reliable estimates of metabolic activity. When assumptions of steady-state and regular breathing are not met, both $\mathrm{VCO}_{2}$ and $\mathrm{VO}_{2}$ may yield biased estimates of metabolic activity. For example, during states of hyperventilation, estimates of metabolic activity based on both $\mathrm{VCO}_{2}$ and $\mathrm{VO}_{2}$ will be biased; however, $\mathrm{VO}_{2}$ may be more robust against such violations than $\mathrm{VCO}_{2}$, due to smaller oxygen stores in the body (Allen, Sherwood, \& Obrist, 1986). Although procedures such as the use of a mask apparanus, as opposed to a mouthpiece, can help minimize the violations of assumptions, one must always be aware that violations can occur.

The use of $\mathrm{VCO}_{2}$ to assess metabolic activity under standard conditions is, therefore, recommended as an option, along with the use of $\mathrm{VO}_{2}$ and EMG, in studies addressing cardiac-metabolic relationships.

\section{REFERENCES}

Allen, M. T., SherwoOd, A.. \& Obrist, P. A. (1986). Interactions of respiratory and cardiovascular adjustments to behavioral stressors. Psychophysiology, 23, 532-541.

Bux. A. S., Stromme, S. B. \& Ursin, H. (1974). Additional hear rate-an indicator of psychological activation. Aerospace Medicine. 45, $1219-1222$

FishmaN, A. P. (1980). Assessment of pulmonary function. New York: McGraw-Hill.

Johnston, D. W.. Anastasiades, P., Vogele, C., Kitson, C., \& SteptoE, A. (1989, December). The relationship between cardiotascular responses in the laboratory and in the field: The importance of active coping. Paper presented at the Sixteenth Annual Meeting of the Psychophysiology Society (British), Bristol, England.

Manuck, S. B., KRantz, D. S. (1986). Psychophysiologic reactivity in coronary heart disease and essential hypertension. In K. A. Matthews et al. (Eds.). Handbook of stress, reactivity and cardiovascular disease (pp. 11-34). New York: Wiley.

Mines, A. H. (1986). Respiratory physiology (2nd ed.). New York: Raven Press.

ObRist, P. A. (1981). Cardiovascular psychophysiology: A perspec tive. New York: Plenum.

Sherwood, A., Allen, M. T., Obrist, P. A., \& Langer, A. W. (1986). Evaluation of beta-adrenergic influences on cardiovascular and metabolic adjustments to physical and psychological stress. Psychophysiology, 23, 89-104.

Stoney, C. M., Langer, A. W. \& Gelling, P. D. (1986). The effects of menstrual cycle phase on cardiovascular and pulmonary responses to behavioral and exercise stress. Psychophysiology, 23, $393-402$.

Stromme, S. B., Wikeby, P. C., Blix, A. S., \& Ursin, H. (1978). Additional heart rate. In $H$. Ursin, E. Baade, \& S. Levine (Eds.), Psychobiology of stress (pp. 83-89). London: Academic Press.

TURNER, J. R. (1989). Individual differences in heart rate response during behavioural challenge. Psychophysiology, 26, 497-505.

TURNER, J. R. (in press). Additional heart rate and the investigation of suprametabolic adjustments during psychological challenge. In J. F. Thayer \& J. S. Tanaka (Eds.), Recent advances in the quantification of psychophysiological data. New York: Plenum.

Turner, J. R., \& Carroll, D. (1985). Heart rate and oxygen consumption during mental arithmetic, a video game, and graded exercise: Further evidence of metabolically-exaggerated cardiac adjustments? Psychophysiology, 22, 261-276.

Turner, J. R., Carroll, D., Costello, M., \& Sims, J. (1988). The effects of aerobic fitness on additional heart rates during active psychological challenge. Joumal of Psychophysiology, 2, 91-97.

Turner, J. R., Carroll, D., \& Courtney, H. (1983). Cardiac and metabolic responses to "space invaders": An instance of metabolicallyexaggerated cardiac adjustment? Psychophysiology, 20, 544-549.

(Manuscript received August 7, 1990; revision accepted for publication December 4,1990 .) 